\title{
A four year dose-response study of recombinant human growth hormone treatment of growth hormone deficient children: effects on growth, bone growth and bone mineralization
}

\author{
Giorgio Radetti ${ }^{1}$, Fabio Buzi ${ }^{2}$, Claudio Paganini ${ }^{1}$, Claudia Martelli ${ }^{2}$ and Silvano Adami ${ }^{3}$ \\ ${ }^{1}$ Department of Pediatrics, Regional Hospital of Bolzano, Italy, ${ }^{2}$ Department of Pediatrics, University of Brescia, Italy and \\ ${ }^{3}$ Department of Rheumatology, University of Verona, Italy \\ (Correspondence should be addressed to G Radetti, Department of Paediatrics, Regional Hospital of Bolzano, via L Boehler no 5, 39100 Bolzano, Italy; \\ Email G.Radetti@ntt.it)
}

\begin{abstract}
To evaluate the effects of two regimens of recombinant human GH (rhGH) on growth, bone growth and bone mineralization in GH deficient children, we studied two groups (A and B), each including 16 GH deficient children matched for sex, age, body mass index, height, height velocity and bone age/ chronological age ratio (BA/CA). Group A was treated with a weekly rhGH dose of $1 \mathrm{IU} / \mathrm{kg}$ and group B with $0.5 \mathrm{IU} / \mathrm{kg}$. After four years of therapy, we evaluated the auxological outcome, bone morphometry (metacarpal index: MI) and bone mineralization by quantitative roentgen microdensitometry at the middle region of the II metacarpal and ultra-distal radius. Height increased significantly in both groups, being significantly higher in group A after four years of therapy, while BA/CA remained similar in the two groups. Bone growth (measured by the MI), and bone mineral density at the metacarpal (mostly trabecular bone) and at the ultra-distal radial (mostly cortical bone) site did not differ in the two groups, nor did these three parameters differ from normal controls.

In conclusion, after four years a greater height gain was achieved by the higher dose of rhGH compared with the conventional dose, but there were no differences in bone growth and mineralization
\end{abstract}

European Journal of Endocrinology 142 42-46

\section{Introduction}

Adult stature in growth hormone (GH) deficient children is usually disappointing (1-3), although retrospective studies suggest that early diagnosis and more intensive GH treatment might improve final height $(4,5)$. Children affected by isolated GH deficiency (GHD) grow better when $\mathrm{GH}$ is given on a daily regimen compared with thrice weekly $(6,7)$, but it is not known whether higher than conventional GH doses result in a better height gain and/or in an improved final height. This issue has been addressed prospectively in a threeyear observational study (8), which showed that GHD children grow better, although not significantly so, when treated with higher $\mathrm{GH}$ doses. Bone mineralization is also positively affected by GH treatment, which is able to reverse osteopaenia in GHD children (9-11). In a short-term study it has been demonstrated that more frequent $\mathrm{GH}$ injections result in a more marked bone mineralization (10), although the long-term effect of higher $\mathrm{GH}$ doses on bone is still unknown. In some conditions other than GHD, such as Turner syndrome or chronic renal failure, a higher GH dose is now commonly administered without significant side-effects $(12,13)$. This means that a higher GH dose might also be given in GHD with the possibility of better effects on growth. Therefore, the aim of this study was to assess the effect of two different $\mathrm{GH}$ doses $(1 \mathrm{IU} / \mathrm{kg}$ per week versus $0.5 \mathrm{IU} / \mathrm{kg}$ per week) on growth, bone growth and bone mineralization in two groups of well-matched prepubertal GHD children. We report here the results of the first four years of treatment.

\section{Subjects and methods}

Out of two cohorts of $\mathrm{GH}$ deficient patients (cohort A: 85 patients treated in Bolzano, Italy, with a weekly GH dose of $1 \mathrm{IU} / \mathrm{kg}$ body weight (bw); cohort B: 73 patients treated in Brescia, Italy, with a weekly dose of $0.5 \mathrm{U} / \mathrm{kg}$ bw), we selected 2 groups (group A and group B respectively), each including $16 \mathrm{GH}$ deficient patients matched for age (mean \pm s.D., group A: 9.53 \pm 3.26 years; group B: $9.78 \pm 3.15$ years; Student's $t$-test: not 
significant (NS)), sex (13 male and 3 female in each group), body mass index standard deviation score (BMISDS) (group A: $-0.5 \pm 1.6$; group B: $0.3 \pm 1.8$; NS), height-SDS (HT-SDS) (group A: $-2.39 \pm 0.6$; group B: $-2.29 \pm 0.6$; NS), height velocity-SDS (HV-SDS) (group A: $-1.68 \pm 0.93$; group B: $-1.75 \pm 0.73$; NS) and bone age/chronological age ratio (BA/CA) (group A: $0.81 \pm 0.15$; group B: $0.78 \pm 0.17$; NS).

The diagnosis of GHD was based on the following criteria: height $<-2$ SDS or $<10$ th centile when corrected for parental target (by means of JM Tanner's 'Parents-allowed-for charts') (14); HV-SDS <25th centile for chronological age when measured for more than 1 year; bone age delay $>2$ years compared with chronological age; peak $\mathrm{GH}<10 \mu \mathrm{g} / \mathrm{l}$ in at least 2 consecutive conventional pharmacological tests (15). In particular, none of the patients had organic GH deficiency or panhypopituitarism or multiple pituitary hormone deficiency, all being affected by idiopathic isolated GHD, as assessed by full endocrine evaluation and either pituitary CT scan or NMR. Peak GH after pharmacological stimulation was similar in the two groups (group A: $4.9 \pm 2.5 \mu \mathrm{g} / \mathrm{l}$; group B: $5.4 \pm 2.7 \mu \mathrm{g} / \mathrm{l}$; NS). At the beginning of the study all patients were prepubertal. In the first year of treatment two patients in group A and one in group B entered into puberty, in the second year 4 patients in group $A$ and 3 in group $B$ were in puberty, in the third year 5 in Group A and 6 in group B were in puberty and at the end of the study 7 patients in each group were pubertal.

All the patients were followed for a minimum of 4 years by regular ( 6 monthly) clinical and auxological assessments; these were set by standard anthropometric techniques (16), and were performed by the same trained observers in each centre.

Each patient in group A (higher GH dose) underwent an oral glucose tolerance test (OGTT) once a year to check possible changes in glucose tolerance.

The following auxological variables were considered for analysis: height-SDS (HT-SDS) (17); bone age (BA), evaluated according to the Greulich and Pyle assessment methodology (18); bone age/chronological age ratio (BA/CA); parental-adjusted HT-SDS, calculated as the difference between mid-parental height-SDS and the actual HT-SDS; body mass index-SDS (BMI-SDS) (19).

Evaluation of cortical thickness and bone density (BMD) was performed at the end of the observation period by radiometric techniques and quantitative roentgen microdensitometry of the metacarpus and ultra-distal radius. This method makes use of the same $\mathrm{X}$-ray pictures which are routinely obtained for the assessment of bone age, as previously described (20). The radiographs were taken with a graduated aluminium reference standard calibrated versus a hydroxyapatite phantom positioned at the level of the styloid process of the radius. The X-ray pictures were analysed by means of a technical device (Radiometer, NIM, Verona, Italy) developed in our laboratory. With this technique the images are 'captured' by a video camera and the grey levels of the digitalized image can be quantified against the reference standard. This allows a more accurate measurement of the cortical area based on an objective method (threshold grey gradient) and the evaluation of BMD, which appears to be significantly related to dual energy X-ray absorptiometry (DEXA) measurements (21). With this method we measured the outer diameter (D), the inner diameter (d), the length of the II metacarpus and the bone mineral content of its middle region $(\mathrm{BMCm})$. This instrument also allowed the evaluation of the bone mineral content (BMCr) and the width $(\mathrm{w})$ of the ultra-distal radius. The distance between the aluminium phantom and the region of interest was always below $3 \mathrm{~cm}$. Assuming a circular sectional area of both the metacarpus and the ultradistal radius, the following parameters were calculated:

metacarpal index $(\mathrm{MI})=(\mathrm{D}-\mathrm{d}) / \mathrm{D}$

medullary area $(\mathrm{MA})=(\mathrm{d} / 2) \times(\mathrm{d} / 2) \times 3.14$

metacarpal cortical area $(\mathrm{MCA})=(\mathrm{D} / 2) \times(\mathrm{dD} 2) \times 3.14$ - MA

ultra-distal radius area $(\mathrm{URA})=(\mathrm{w} / 2) \times(\mathrm{w} / 2) \times 3.14$

bone mineral content (BMC) corrected for the crosssectional area $=\mathrm{BMCm} / \mathrm{MCA}$, for mid-metacarpus (BMDmet) and $\mathrm{BMCr} / \mathrm{URA}$, for ultra-distal radius (BMDrad).

The coefficients of variation (CV\%) within the same X-ray are $1.5 \%, 1.1 \%$ and $1.8 \%$ for the MI, metacarpal BMD and radial BMD respectively. We previously demonstrated that there is a highly significant linear correlation between the volumetric density, calculated by dividing the BMC by both bone width and depth, and the volumetric density, calculated assuming a circular cross-sectional area of the two bone segments, with an interception and a slope very close to zero and one respectively. The data have been plotted against our published reference data (20) and are expressed as SDS for sex and bone age, since bone mineral density is known to correlate better with bone age than with chronological age (22). Results are expressed as means \pm S.D.

\section{Statistical analysis}

Paired analysis of variance (ANOVA) with Bonferroni's post-hoc correction was used to evaluate the changes in HT-SDS during the observation period; Student's unpaired $t$-test was used to evaluate possible differences in the above mentioned variables between the two groups.

\section{Results}

\section{Auxology}

HT-SDS (Fig. 1) was similar in both groups at the beginning of treatment (group A: $-2.39 \pm 0.6$; group B $-2.29 \pm 0.6$; NS) and improved in both groups following therapy (ANOVA: $P<0.001$ for both group 


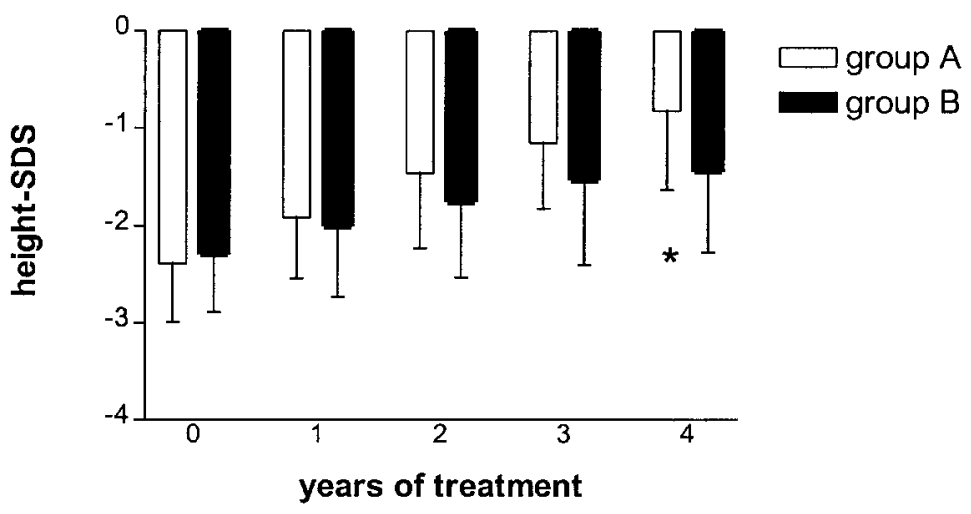

Figure 1 Height-SDS in the group treated with high doses (group A, open bars) and conventional doses (group B, solid bars) of $\mathrm{GH}$ during the four years of observation. ${ }^{*} P<0.05$ for the difference between the two groups.
A and group B). HT-SDS, however, was significantly higher in group A after 4 years $(P<0.05)$. Height gain, as measured by the difference between HT-SDS at the 4th year of treatment and HT-SDS at the beginning of treatment, was greater in group A $(1.5 \pm 0.81)$ than in group $\mathrm{B}(0.87 \pm 0.66)(P=0.03)$.

The bone age/chronological age ratio was similar in both groups before GH therapy and did not increase significantly after 4 years (Table 1).

Parental-adjusted HT-SDS showed no statistical difference in the two groups either at the beginning or at the end of the study (Table 1); however, the increment of parental-adjusted HT-SDS after four years was significantly greater in group A $(P<0.005)$.

BMI-SDS was similar in the two groups at the beginning of the study and did not change significantly after 4 years of treatment (Table 1).

The MI-SDS, as well as the BMD-SDS evaluated at the metacarpal site (BMDmet) (which represents predominantly cortical bone) and at the ultra-distal radial site (BMDrad) (which is predominantly trabecular bone), were not different in the two groups. There was also no statistical difference when the three variables were evaluated against zero (Table 2).

No side-effects nor adverse events were observed in either group during the study; all the patients in group A showed normal OGTT throughout the four-year observation period.

\section{Discussion}

In this study we have shown that after 4 years of treatment, a higher dose regimen of rhGH effectively results in a significantly better height gain in GHD patients, without influencing the pattern of bone maturation, growth and mineralization.

Concerning growth, our data extend the observations of a previous 3-year duration study where better results were obtained with higher doses in the short term but not in the long term (8). During the study, growth was more sustained in the group treated with higher doses, thus resulting in a more marked reduction of the height deficit after four years. This is even more apparent when the net height gain is considered and, furthermore, when the actual height gain is plotted against the parental HT-SDS. The 'delta' of the parentaladjusted HT-SDS, i.e. the real gain against the genetic target, is thus significantly higher in the group treated with higher doses. It must also be pointed out that this increment was not obtained at the expense of a faster bone maturation, because the chronological age/bone age ratio remained constant throughout the period of observation.

The evaluation of the results, however, cannot leave the costs of treatment out of consideration. We calculated that the actual difference in SDS (0.52 SDS $=4.2 \mathrm{~cm}$ ) between the two groups, obtained with

Table 1 Auxological characteristics of the two groups of GHD patients at the beginning and after 4 years of GH treatment. Results are expressed as means \pm S.D.

\begin{tabular}{lccccr}
\hline & \multicolumn{2}{c}{ Group A } & & \multicolumn{2}{c}{ Group B } \\
\cline { 2 - 3 } \cline { 5 - 6 } & 0 years & 4 years & & 0 years & 4 years \\
\hline BA/CA & $0.81 \pm 0.14$ & $0.88 \pm 0.07$ & & $0.78 \pm 0.17$ & $0.84 \pm 0.12$ \\
BMI-SDS & $-0.46 \pm 1.60$ & $0.01 \pm 1.29$ & & $0.26 \pm 1.80$ & $0.51 \pm 1.85$ \\
Parental-adjusted HT-SDS & $-1.66 \pm 0.96$ & $-0.02 \pm 0.9$ & & $-1.3 \pm 1.24$ & $-0.33 \pm 1.3$ \\
'Delta' parental-adjusted HT-SDS & \multicolumn{2}{c}{$1.67 \pm 0.88^{*}$} & & \multicolumn{2}{c}{$0.87 \pm 0.66$} \\
\hline
\end{tabular}

${ }^{*} P<0.005$ for the difference between the two groups. 
Table 2 Bone morphometry and mineralization in the two groups of GHD patients after 4 years of $\mathrm{GH}$ treatment. Results are means \pm S.D.

\begin{tabular}{llrr}
\hline & MI-SDS & BMDmet-SDS & BMDrad-SDS \\
\hline Group A & $0.45 \pm 0.6$ & $-0.18 \pm 0.41$ & $-0.006 \pm 0.58$ \\
Group B & $0.15 \pm 0.07$ & $0.13 \pm 0.58$ & $0.005 \pm 0.49$ \\
\hline
\end{tabular}

the two different regimens, cost roughly $\$ 625000$ ! We think that this point must also be taken into account when evaluating the results.

Concerning bone, our results cannot be compared with similar studies because, to our knowledge, no other study has been published that confronted the effects of two different GH doses on bone growth and mineralization in the long term. Nevertheless, we have shown that bone parameters were in the normal range in both groups after GH therapy. This is in agreement with a recent study in which the metacarpal index was similarly evaluated, showing unaltered bone proportions during the first three years of GH therapy (23), and with another report showing a progressive normalization of the bone mineral density in GHD children after long-term GH treatment (24). It does not seem, however, that higher doses of $\mathrm{GH}$ than those usually employed have a different influence on bone growth and/or mineralization. In fact, after a four-year treatment, the metacarpal index, which is a good indicator of cortical bone thickness (i.e. bone growth), and the bone mineral density at the metacarpal site (predominantly cortical bone) as well as at the radial site (predominantly trabecular bone) were similar and, in particular, were not different from those seen in normal children. When interpreting the bone data, however, it should be considered that this was a cross-sectional study and that the bone status of the subjects before starting treatment was unknown. Therefore, it would be inappropriate to draw conclusions about the real effect of the two different $\mathrm{GH}$ regimens on the increment of bone growth and mineralization.

Apart from the results of this study, one must also consider the possible negative influences of high rhGH doses on insulin sensitivity and on cardiac function. Although reduced insulin sensitivity is a well known consequence of GH treatment (25), significant changes in glucose tolerance are very rarely induced, even in children at risk of diabetes such as girls with Turner's syndrome (26). Moreover, all the patients on high GH doses had a normal OGTT throughout the study.

In conclusion, higher doses of rhGH appear to result in an improved height gain during a four-year period of treatment; however, before changing our conventional approach to the treatment of GHD children, we must await the data on the final height of our patients.

\section{References}

1 Burns EC, Tanner JM, Preece MA \& Cameron N. Final height and pubertal development in 55 children with idiopathic growth hormone deficiency, treated for between 2 and 15 years with human growth hormone. European Journal of Pediatrics 1981137 155-164.

2 Bundak R, Hindmarsh PC, Smith PJ \& Brook CGD. Long-term auxological effects of human growth hormone. Journal of Pediatrics $1988112875-879$

3 Frisch H \& Birnbacher R. Final height and pubertal development in children with growth hormone deficiency after long-term treatment. Hormone Research 199543 132-134.

4 Blethen SL, Baptista J, Kuntze J, Foley T, Lafranchi S \& Johanson A. Adult height in growth hormone $(\mathrm{GH})$-deficient children treated with biosynthetic GH. The Genentech Growth Study Group. Journal of Clinical Endocrinology and Metabolism 199782 418-420.

5 Ranke MB \& Lindberg A. Growth hormone treatment of idiopathic short stature: analysis of the database from KIGS, the Kabi Pharmacia International Growth Study. Acta Paediatrica (Suppl) $199440618-23$.

6 Kastrup KW, Sandahl Christiansen J, Koch Andersen J \& Orskow H. Increased growth rate following transfer to daily s.c. administration from three weekly i.m. injections of hGH in growth hormone deficient children. Acta Endocrinologica 1983 $104148-152$

7 Albertsson-Wikland K, Westphal O \& Westgren U. Daily subcutaneous administration of human growth hormone in growth hormone deficient children. Acta Paediatrica Scandinavica 1986 75 89-97.

8 De Muinck Keizer-Schrama S, Rikken B, Hokken-Koelega A, Witt JM, Drop S \& the Dutch Growth Hormone Working Group. Comparative effect of two doses of growth hormone for growth hormone deficiency. Archives of Diseases in Childhood $19947112-18$

9 Saggese G, Baroncelli GI, Bertelloni S, Cinquanta L \& DiNero G. Effects of long-term treatment with growth hormone on bone and mineral metabolism in children with growth hormone deficiency. Journal of Pediatrics 1993122 37-45.

10 Zamboni G, Antoniazzi F, Radetti G, Musumeci C \& Tatò L. Effect of two different regimens of hGH therapy on bone mineral density of patients with GH deficiency. Journal of Pediatrics 1991119 483-485.

11 Boot AM, Engels MA, Boerma GJ, Krenning EP \& DeMuink Keizer-Schrama SM. Changes in bone mineral density, body composition, and lipid metabolism during growth hormone $(\mathrm{GH})$ treatment in children with GH deficiency. Journal of Clinical Endocrinology and Metabolism 199782 2423-2428.

12 Rosenfeld RG, Frane J, Attie KM, Brasel JA, Burstein S, Cara JF et al. Six year results of a randomised prospective trial of human growth hormone and oxandrolone in Turner syndrome. Journal of Pediatrics $199212149-55$.

13 Hokken-Koelega ACS, Stijnen T, DeJong MCJW, Donckerwolcke RA, De Muinck Keizer-Schrama SM, Blum WF \& Drop SL. Double-blind trial comparing the effects of two doses of growth hormone in prepubertal patients with chronic renal insufficiency. Journal of Clinical Endocrinology and Metabolism 1994 79 1185-1190.

14 Tanner JM. Fetus into Man: Physical Growth from Conception to Maturity, edn 2. Ware: Castelmead Publications, 1989.

15 Cowell CT. Short stature. In Clinical Paediatric Endocrinology, edn 3, pp 136-172. Ed CGD Brook. Oxford: Blackwell Science, 1994.

16 Cameron N. Methods of auxological anthropometry. In Human Growth, vol III, pp 3-46. Eds F Falkner \& JM Tanner. New York: Plenum Press, 1986.

17 Tanner JM, Whitehouse RH \& Takaishi M. Standards from birth to maturity for height, weight, height velocity and weight velocity: British children 1965. Archives of Diseases in Childhood $196641613-635$. 
18 Greulich WW \& Pyle SL. Radiographic Atlas of Skeletal Development of the Hand and Wrist, edn 2. Stanford, CA: Stanford University Press, 1969.

19 Rolland-Cachera MF, Cole TJ, Sempé M, Tichet J, Rossignol C \& Charraud A. Body mass index variations: centiles from birth to 87 years. European Journal of Clinical Nutrition $19914513-21$.

20 Zamberlan N, Radetti G, Paganini C, Gatti D, Rossini M, Braga V \& Adami S. Evaluation of cortical thickness and bone density by roentgen microdensitometry in growing males and females. European Journal of Pediatrics 1996155 377-382.

21 Adami S, Zamberlan N, Gatti D, Zanfisi C, Braga V, Broggini M \& Rossini M. Computed radiographic absorptiometry and morphometry in the assessment of postmenopausal bone loss. Osteoporosis International $199668-13$.

22 Ilich JZ, Hangartner TN, Skugor M, Roche AF, Goel PK \& Matkovic V. Skeletal age as determinant of bone mass in preadolescent females. Skeletal Radiology 199625 431-439.

23 Bettendorf M, Graf K, Nelle M, Heinrich UE \& Tröger J. Metacarpal index in short stature before and during growth hormone treatment. Archives of Diseases in Childhood 199879 165-168.
24 Saggese G, Baroncelli GI, Bertelloni S \& Barsanti S. The effect of long-term growth hormone $(\mathrm{GH})$ treatment on bone mineral density in children with GH deficiency. Role of $\mathrm{GH}$ in the attainment of peak bone mass. Journal of Clinical Endocrinology and Metabolism 199681 3077-3083.

25 Bratusch-Marrain PR, Smith D \& DeFronzo RA. The effects of growth hormone on glucose metabolism and insulin secretion in man. Journal of Clinical Endocrinology and Metabolism 198255 973-982.

26 Caprio S, Boulware SD, Press M, Scherwin RS, Rubin K, Carpenter TO, Plewe G \& Tamborlane WV. Effect of growth hormone treatment on hyperinsulinemia associated with Turner's syndrome. Journal of Pediatrics 1992120 238-243.

Received 15 February 1999

Accepted 6 September 1999 